\title{
De onde vêm essa voz e seu grito? Reflexões sobre o primeiro Jorge Amado, protagonista do romance de 1930
}

\author{
Thiago Mio Salla \\ Roberto Amado
}

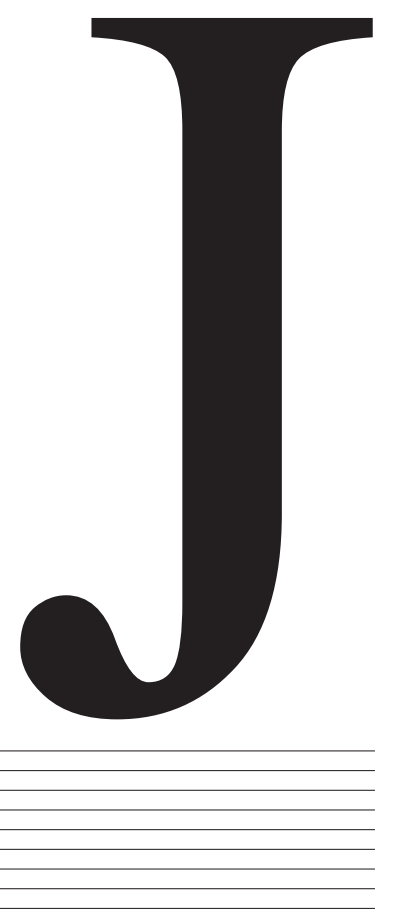

orge Amado emergiu do anonimato, ainda muito jovem, para rapidamente ganhar notoriedade graças a duas atividades que caracterizaram sua literatura nesses anos. Uma delas foi a reconhecida produção de seus primeiros quatro livros, obras que consolidaram sua voz literária emergente junto ao público e à crítica. A outra, menos visível atualmente, refere-se à sua vasta publicação

THIAGO MIO SALLA é professor e pesquisador da ECA/USP e do Programa de Pós-Graduação em Estudos Comparados de Literaturas de Língua Portuguesa da FFLCH/USP.

ROBERTO AMADO é jornalista, escritor e mestrando no Programa de Pós-Graduação em Estudos Comparados de Literaturas de Língua Portuguesa da FFLCH/USP. 
de artigos em jornais e revistas literárias da época, por meio da qual o autor baiano revela uma outra voz, a do crítico ferino, ousado, até mesmo atrevido. Nesses textos, ele não só estabelece critérios estéticos e formais da nova literatura então emergente, como também tece uma malha de argumentos e parâmetros pessoais a partir dos quais determina alguns paradigmas de uma literatura considerada "moderna" (termo que empregou com frequência) e o papel dos escritores que a praticavam.

A soma de tais vozes permitiu a Jorge Amado assumir a condição de figura de proa de uma das mais importantes expressões literárias das letras brasileiras no século XX: o romance de 1930. Assim, mostra-se inevitável que suas reflexões, expressas tanto nas obras quanto nos artigos, também sejam, em certo sen-

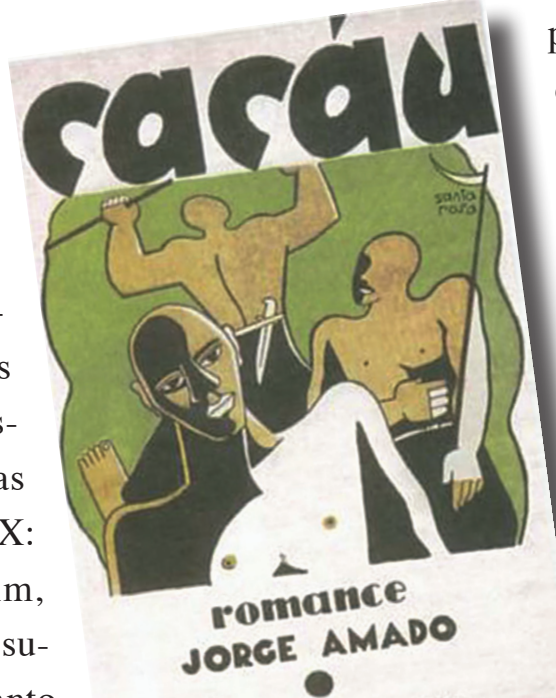
ARIEL EDITORA, LTD. principalmente, de conteúdo, representativa das múltiplas transformações que tomaram corpo na década de 1930.

"Pelas suas peculiaridades de forma e conteúdo, Cacau é um romance característico dos anos 30, quando a radicalização político-ideológica que na Europa preparou terreno para a Segunda Guerra Mundial vem repercutir no Brasil sob forma de um anseio por reformas político-sociais de base" (Paes, 1991, p. 10).

Quando se refere à "radicalização político-ideológica", José Paulo Paes tem em vista a definitiva polarização entre esquerda e direita no Brasil: de um lado, o pensamento conservador representado, entre outros, pela reação católica e pelo integralismo de Plínio Salgado; de outro, sobretudo, o tido, as do próprio romance de 1930, uma vez que artista e movimento literário estão intimamente ligados. A partir sobretudo de posicionamentos de época do próprio autor e de críticos de diferentes matizes, o presente artigo limita-se a apresentar sumariamente o quadro que antecede os anos 1930, avançando até o romance $\mathrm{Ca}$ cau (1933), segundo livro de Jorge Amado, tido como uma espécie de materialização do processo analítico por ele empreendido enquanto crítico ${ }^{1}$. O referido romance se mostra paradigmático da etapa que se seguiu ao Modernismo de 1922, não tanto por suas qualidades literárias, mas sim por congregar uma nova proposta estética e,
1 Não cabe, nesta proposta, abordar o considerado primeiro romance de Jorge Amado, O país do carnaval, cujas características, embora pertinentes, não são tão modelares dos anos 1930 como Cacau. De fato, Bueno, ao se referir a O país do carnaval e a outras obras lançadas em 1929-1930 (como Inquietos, de Luís Delgado), reconhece a sua importância como "elementos de transição", mas destaca que, em tais obras, "o esteticismo, o afastamento da realidade [...] não conduz a nenhum tipo de transformação e, portanto, não serve para essa nova geração" (Bueno, 2002, p. 107). 
ditadura do Estado Novo. Nesse cenário, cujas raízes, de certa maneira, podem ser encontradas nos anos 1920, toma lugar e ressoa a voz do autor baiano.

\section{HOMENS DE LETRAS E MODERNISMO}

José Osório de Oliveira, grande conhecedor da literatura brasileira, cabo-verdiana e portuguesa, figura respeitada por autores e críticos tanto de Portugal quanto do Brasil, aponta de modo sintético, em obra aclamada por Mário de Andrade $^{2}$, algumas condições gerais que desembocaram no grande desenvolvimento da literatura brasileira dos anos 1930.

"Os problemas do Brasil: o seu meio geográfico, a sua formação histórica, a sua constituição etnológica, a sua vida social, a sua organização política, o seu regime econômico, vinham preocupando os brasileiros conscientes..." (Oliveira, 1939, p. 114).

Logo de saída, é possível perceber alguns aspectos eloquentes e até mesmo conclusivos na frase. Em primeiro lugar, faz-se interessante notar a abrangência dos “problemas do Brasil" apontados pelo crítico português: contempla praticamente todos os setores da vida social, econômica e cultural do país. Não fosse pela quase

2 Trata-se de História breve da literatura brasileira (1939), compêndio referido pelo autor de Macunaíma como "o mais apaixonante, o mais inteligentemente sintetizado, mais alertamente crítico dos breviários da nossa literatura. [...] é tão sugestiva, tão cheia de ideias e de pontos de vista curiosos, que embora escrita para portugueses, me parece indispensável a qualquer brasileiro" (Andrade, 1972, p. 175). trágica consistência e intensidade da questão, ela seria possivelmente quase cômica. Afinal, uma nação com essa profundidade de questões estaria, teoricamente, mais próxima de produzir miséria do que um vigoroso movimento literário - ou talvez, por isso mesmo, seja capaz de produzir ambos. Em segundo lugar, pode-se depreender que, por mais conhecedor de nossa terra e de nossa gente, e especificamente de nossa literatura, o olhar português de Osório de Oliveira não deixa de adotar um ponto de vista externo, distante, não tão imerso nas circunstâncias políticas e sociais que envolviam o país naquele momento. Valendo-se dessa perspectiva, seria, portanto, capaz de fazer uma leitura mais ampla, e menos visceral, dos elementos motivadores de nossa literatura, desprendendo-se de alguns conceitos já de certo modo consolidados àquela altura ${ }^{3}$.

Há ainda um terceiro aspecto importante na referida frase, o qual se reporta a uma classe de "brasileiros conscientes", ou seja, um público leitor crescente e cada vez mais interessado numa literatura com as características do romance de 1930. Em termos quantitativos, trata-se de um dado novo entre as elites culturais brasileiras, cujo olhar tinha sido, até os anos 1920, sobretudo, historicamente eurocêntrico.

Mas... por que esse "súbito interesse" do público? Talvez a explicação seja complexa demais para que se possa abarcar toda a sua tessitura (ainda mais nos limites reduzidos

3 Convém assinalar que, publicada em 1939, a referida História breve da literatura brasileira, de José Osório de Oliveira, revela certa distância temporal dos elementos históricos que formataram as origens do romance de 1930 . 
do presente artigo), mas novamente a perspectiva de Osório de Oliveira contribui, com seu olhar externo e capacidade comparativa, para lançar luz a essa questão.

"O homem de letras no Brasil (o homem de letras de hoje, que se libertou do preconceito intelectualista europeu) está, de certo modo, em pé de igualdade com o povo; compartilha, muitas vezes, dos mesmos gostos, sentimentos e ideias; tem, ou adota, muitos de seus usos e costumes. Isso, simplesmente porque a cultura social é, no Brasil, mais forte que a cultura a que chamamos de intelectual, para a distinguir da cultura viva do povo, a cultura sinônimo de experiência humana" (Oliveira, 1939, p. 119).

É louvável a elegância crítica de Oliveira e, por certo, esclarecedora de um ponto de vista mais sofisticado e conceitual. Mas para aquele Jorge Amado em começo de carreira, procurando (e conquistando) seu espaço como escritor e crítico, a literatura que então surgia estava binariamente dividida entre obras e artistas de segunda categoria e os que realmente representavam os novos ares da cultura.

Em artigo sobre o livro Figueira velha, por exemplo, faz um elogio dúbio ao autor gaúcho Telmo Vergara: “[...] ainda há de realizar uma obra definitiva quando se voltar para assuntos de maior força humana, de maior densidade, para assuntos mais fundos e menos literários" (Amado, 1935b, p. 6). No mesmo artigo, ao tratar de um dos personagens do livro, o poeta Marcos, Amado aproveita para destilar suas ideias corrosivas sobre escritores que praticam poesia na vida real, atribuindo um tom claramente pejorativo às manifestações "literárias" ao definir o personagem: "[...] poeta sem ter o que fazer, poeta sem assunto [...]. Poeta bem literato, bem literato mesmo, cheio de angustiazinhas bem calculadas, bem literárias" (p. 6). E, como se não fizesse parte desse universo composto por pretensos escritores, lança seu olhar contundente para um tipo de intelectual que parece estar nas vizinhanças: "O poeta Marcos existe, sim. [...] Literário e artificial, igualzinho [...] no fundo até um bom rapaz que se formará em direito e terminará na redação de um jornal, esquecido das tragédias e pensando em arrancar um vale do gerente" (p. 6) ${ }^{4}$.

Já orientado por suas convicções literárias, em 1932, com apenas 20 anos e um livro publicado ( $O$ país do carnaval), exibe sua audácia ao escrever um artigo sobre Evolução da poesia brasileira, de Agrippino Grieco, obra então recém-lançada: "Decididamente, um homem desses [...] não pode ser amado num país de homens que escrevem versos chorões, louvam os discursos de todos os ministros e onde o elogio mútuo impera" (Amado, 1932, p. 1). Se louva o ambicioso livro de um dos fundadores da Editora Ariel, dirige sua ferocidade aos integrantes da Academia Brasileira de Letras, até como modo de fortalecer suas convicções. "O sr. Gustavo Barroso concedeu uma entrevista a um jornal de Minas na qual afirmou que os acadêmicos ou eram velhos que nem sabiam morrer ou moços preguiçosos e inúteis. Talvez fosse esta a primeira coisa certa que o cabuloso escritor de cinquenta livros ruins tenha dito" (Amado, 1933a, s.p.).

4 Ironicamente, Jorge Amado, àquela altura (1935), tinha acabado de se formar em Direito e vivia nas redações das revistas literárias (Tati, 1961, p. 20). 
Paralelamente, há, durante essa década, a "clara expressão de um desejo de modificação do Brasil", atrelado ao "processo de plena implantação do capitalismo no país e do fluxo ascensional da burguesia, dois fatores que mexem com as demais camadas sociais [...]" (Lafetá, 2000, p. 27). Tal conjuntura, na qual avultam, entre outros movimentos, Modernismo, tenentismo e comunismo (Duarte, 1996, p. 20), repercute na elaboração formal do romance de 1930 e no desenvolvimento literário de seus autores, ganhando substância e materialidade desde as primeiras obras lançadas na década de 1930, com destaque para aquelas da lavra de escritores que surgem nesse momento, como Rachel de Queiroz, Amando Fontes e, naturalmente, Jorge Amado. Cabe a eles erguer a bandeira com novos dizeres, plenos de conteúdo social.

Apesar de algumas polêmicas que normalmente envolvem a discussão da ressonância e repercussão do movimento modernista no romance de 1930, há algumas reflexões predominantes. As inovações literárias consolidadas pelo movimento, tanto formais como estéticas, somadas à deliberada rejeição aos velhos padrões, permitem que os autores de 1930 pratiquem esses novos paradigmas de maneira confortável: “[...] o inconformismo e o anticonvencionalismo se tornaram um direito, não uma transgressão, fato notório mesmo nos que ignoravam, repeliam ou passavam longe do modernismo" (Candido, 1989, p. 186). Lafetá, apoiado por Candido, desenvolve os conceitos de "projeto estético" e "projeto ideológico" para definir a diferença básica entre a fase heroica da literatura modernista, em que se “discute principalmente a linguagem", e a fase que se segue à Revolução de 1930, em que "discute-se a função da literatura, o papel do escritor, as ligações da ideologia com a arte" (Lafetá, 2000, p. 28). No que se refere à gênese do romance de 1930 , Lafetá encontra uma ligação didática entre os dois movimentos literários, pela qual é possível identificar um processo lógico de evolução formal e estética.

“[...] o Modernismo, por volta de 30, já teria obtido ampla vitória com seu programa estético e se encontrava, portanto, no instante de se voltar para outro tipo de preocupação [...] enquanto nos anos vinte o projeto ideológico do Modernismo correspondia à necessidade de atualização das estruturas [...]" (Lafetá, 2000, p. 28).

Ainda que essa "ligação didática" tenha substância, também determina limites estreitos dessa literatura praticada após a década de 1930, reduzindo a independência de sua voz: “[...] o estudo de Lafetá - como de resto qualquer estudo - paga o seu tributo ao tempo em que foi escrito e acaba repetindo um pouco o que ele mesmo condena: julgar a literatura a partir do plano ideológico" (Bueno, 2015, p. 46). Mas essa não é a única restrição a tal proposta que condiciona a literatura ao advento do Modernismo, como ponto central de referência. As interpretações relativas a essa questão, principalmente quando envolvem o romance de 1930, estão cercadas de uma tensão que parece inevitável. Lafetá reconhece apenas tangencialmente uma recusa ao Modernismo pela geração de escritores do romance de 1930. Já Luís Bueno, em Uma história do romance de 30 , abdica do princípio de continuidade pacífica invocado por Lafetá: 
ao descer à arraia miúda da produção crítica e romanesca da época, ele tematiza a forte tensão entre a literatura de 1922 e a produzida depois da revolução de outubro. Em vez de considerar que existiria um único movimento dividido em duas fases, Luís Bueno entende que estariam em jogo dois movimentos literários e geracionais: o Modernismo e o pós-Modernismo, este englobando os artistas imediatamente situados após o Modernismo de 1922 (cf. Salla, 2015, p. 119).

Jorge Amado, em suas críticas publicadas no começo da década de 1930, tenta, em alguns momentos (mas nem sempre), adotar uma política de boa vizinhança em relação às repercussões do Modernismo sobre sua obra e a de seus colegas de geração ${ }^{5}$. Reconhecendo o valor do movimento de 1922, o escritor baiano, no papel de protagonista das ideias e ideais do romance de 1930, escreve que aquela expressão literária foi importante por ter destruído "muita coisa", referindo-se aos padrões estéticos e formais que o movimento questionou - "embora não tenha construído nada" (Amado, 1934a, p. 49). É curioso notar que, mesmo reconhecendo de modo parcial a relevância do Modernismo no continuum da literatura brasileira e, principalmente, em suas próprias obras, Jorge Amado procura insistentemente uma diferenciação, não apenas por ser óbvia,

5 Em crônica de 1934, ao recuperar lembranças pessoais relativas à sua iniciante atividade literária, no final da década de 1920, compara impiedosamente o Modernismo, que chegava tardio à Bahia, a uma prostituta: "Em 1928 o Modernismo, que acabara em São Paulo, desembarcava na Bahia, como estas rameiras que vão de um lugar para outro para rejuvenescer" (Amado, 1934b, p. 5). mas porque se fazia necessário extrair dessa diferença uma racionalização, ou uma teorização, convincente. Como um menino mais novo que compete com seu irmão mais velho, convencido de que já o superou.

"O romance de invenção, o romance que não se basear na realidade, não resistirá ao tempo e o máximo que pode alcançar será um sucesso do momento... Terá realizado o máximo de beleza o romancista que der ao seu romance o máximo de vida. E quando os homens atravessam uma época política, uma época de lutas como a nossa, o romance que seja honesto não pode deixar de ser uma arma de luta. As revoluções puramente literárias não produzem grandes romancistas. Grandes poetas, grandes ensaístas, mas não grandes romancistas. Cadê o grande romance modernista?" (Amado, 1935c, p. 19).

Por um conjunto expressivo de posicionamentos como esse, seja de demarcação de fronteiras em relação ao passado, seja de definição do papel do homem de letras no presente, pode-se dizer que Jorge Amado foi percebido como protagonista no primeiro lustro da década de 1930, período do qual participou ativamente como ponta-de-lança nos debates intelectuais então travados. Nunca é demais lembrar que o aludido "protagonismo" não se refere ao mérito de sua obra ou de sua atuação pessoal e profissional - embora esses aspectos possam ter influência decisiva na qualificação de um protagonista. Para além de tais questões de ordem mais subjetiva, no caso de Jorge Amado é possível recorrer a alguns aspectos objetivos que corroboram a afirmação de seu papel de destaque. 
No espaço de tempo abordado neste texto, entre 1931 e 1935, Jorge Amado lançou quatro obras reconhecidas, à época, pela sua importância: $O$ país do carnaval (1931), Cacau (1933), Suor (1934) e Jubiabá (1935) ${ }^{6}$. Ao longo do referido período, o autor baiano publicou, nas principais revistas literárias e publicações da época, um número estimado de artigos, crônicas ou críticas superior a 200. Paralelamente, nesse mesmo intervalo temporal, sua obra e sua atuação como escritor foram tema de mais de 300 textos também estampados nas principais publicações do país. Em tais periódi$\cos ^{7}$, as menções à sua participação em palestras, concursos literários como júri, atividades político-culturais, opiniões sobre manifestações diversas da cultura e da política, relatos de suas viagens e contatos com

6 Em 1932, redigiu o livro Rui Barbosa n 2, que nunca foi publicado. Em 1934, escreveu ainda, juntamente com Mathilde Garcia Rosa, sua esposa, o livro infantil Descoberta do mundo.

7 As informações a respeito da presença de Jorge Amado na imprensa foram obtidas a partir de pesquisa em cerca de 20 periódicos (revistas literárias ou mesmo veículos de informações gerais, tais como Boletim de Ariel, Lanterna Verde, Momento, Diário da Noite, Diário de Pernambuco, Dom Casmurro) editados em Pernambuco, Bahia, São Paulo e, em sua grande maioria, no Rio de Janeiro. autoridades da cultura do Brasil e de fora dele ganham espaço, numa estimativa geral, no mínimo toda semana $^{8}$. Entre outros aspectos, a conceituação do romance social do Nordeste pulula em tais páginas.

\section{O NORDESTE}

José Paulo Paes elabora uma análise precisa do que significou a produção literária sobre a realidade nordestina da época, executada por escritores do chamado "Norte" - para citar alguns, Rachel de Queiroz, Amando Fontes, José Lins do Rego, Graciliano Ramos e, obviamente, Jorge Amado:

"O choque de ideologias e a ânsia de reformas sociais que marcaram o Zeitgeist dos anos 1930 brasileiro tiveram no chamado 'romance do Nordeste' desses anos a sua melhor representação literária" (Paes, 1991, p. 11).

A materialização desse Zeitgeist, via "romance do Nordeste", manifesta-se em vários

8 Dados colhidos na pesquisa de mestrado em andamento O primeiro Jorge Amado em jornal e em livro: as crônicas e romances do escritor baiano como protagonista do romance de 1930, realizada por Roberto Amado, sob a orientação de Thiago Mio Salla, no âmbito do Programa de Estudos Comparados de Literaturas de Língua Portuguesa (FFLCH/USP). 
níveis. A começar pela linguagem literária, utilizada, sem receio, já nas primeiras obras da década de 1930. Ou seja, o aspecto "nordestino" negado por José Américo de Almeida em A bagaceira, devido talvez a um rigor literário, passava a ser, então, empregado com desenvoltura em obras como O quinze, de Rachel de Queiroz, Calunga, de Jorge de Lima, Os corumbas, de Amando Fontes, e especialmente Cacau, de Jorge Amado, entre outras 9 .

Este é um dos aspectos mais importantes na caracterização do movimento de 1930 e, especificamente, da obra de Jorge Amado: a confortável ousadia de incorporar e recriar a linguagem popular do nordestino nos diálogos e até mesmo em algumas passagens da narração e descrição, sem comprometer em definitivo as estruturas básicas da norma culta, adotando, assim, um “colorido" idiossincrático ao fazer literário.

9 De fato, A bagaceira constituiu uma das portas que o romance de 1930 e Jorge Amado, em específico, utilizam para encontrar seus próprios caminhos literários. As referências ao ambiente nordestino, a suas paisagens incendiadas pelo calor causticante, povoadas por retirantes e castigadas pelas relações de dominação do patrão sobre o empregado, ao abuso sexual "autorizado" pela hierarquia e pelas relações familiares contaminadas pela hipocrisia são elementos presentes na obra do romancista baiano desde Cacau. É verdade que ele reconheceu a importância do livro de José Américo de Almeida, atribuindo-Ihe a condição de pioneiro (Amado, 1935a, pp. 158-9). Mas a obra não se salva da sua crítica iconoclasta. Em um artigo sobre o livro O gororoba, de Lauro Palhano, Jorge Amado usa $A$ bagaceira como referência para elaborar uma observação contundente a respeito da linguagem utilizada por ambos: "Sofre esse romance de um mal que aparece também em A Bagaceira. Como o livro do Sr. José Américo, $O$ Gororoba tem trechos escritos na mais saborosa linguagem brasileira e páginas em português puxado a clássico, caindo na retórica tola dos discursadores baratos [...]. Um volume entupido de defeitos, sem dúvida. O autor é a toda hora tentado a fazer filosofia [...]" (Amado, 1933b, p. 71).
“A revolução estética de 1922 propicia ao autor [Jorge Amado] régua e compasso expressivos, abrindo-lhe a perspectiva da linguagem desabusada, império da oralidade, além de mostrar o caminho dos estratos recalcados de nossa formação cultural, que até hoje fornecem matéria-prima a suas narrativas" (Duarte, 1996, p. 20).

Tal aspecto revela-se até mesmo como um dos que justificam a popularidade da obra de Jorge Amado desde os primeiros momentos - característica que, aliás, se estendeu a toda a sua produção nas décadas seguintes: "Romances feitos com uma liberdade de narração e linguagem antes desconhecida" (Candido, 1989, p. 187).

Mas, muito além da atraente oralidade de Jorge Amado, há outros fatores que justificam sua popularidade logo nas primeiras obras. Havia um sonho em pauta no qual o segmento letrado da sociedade estava interessado naquele momento, nos primórdios dos anos 1930: “[...] Amado quer pegar o sonho com as mãos, para com elas fazer a literatura do oprimido" (Duarte, 1996, p. 18). Há um interesse multiplicado dos leitores pela realidade nacional, pela vida das camadas mais baixas da população, em que o conceito de "país novo" é substituído por "país subdesenvolvido", resultando em uma "voga" que deriva do fato de "todo o País ter tomado consciência de uma parte vital, o Nordeste, representado na sua realidade viva pela literatura" (Candido, 1989, p. 187).

Indo um pouco mais além nesse raciocínio, com o propósito de refletir sobre o referido conceito de "Zeitgeist dos anos 1930" formulado por Paes, cabe citar uma referência utilizada por Lafetá ao comparar 
as duas décadas, a de 1920 e a de 1930, para além das questões literárias, o que chamou de "consciência do atraso", extraindo, ele mesmo, uma proposição de Mário Vieira de Mello (1963, pp. 3-17):

"Nos anos vinte a tomada de consciência é tranquila e otimista, e identifica as deficiências do país - compensando-as - ao seu estatuto de 'país novo'; nos anos trinta dá-se início à passagem para a consciência pessimista do subdesenvolvimento, implicando atitude diferente diante da realidade" (Lafetá, 2000, p. 29).

Assim, os autores de 1930, em especial Jorge Amado, escrevem livros que tematizam o subdesenvolvimento do Nordeste, com uma dupla necessidade - a de revelar e a de denunciar. São, no entanto, majoritariamente, demandas de caráter social e cultural, e não explicitamente político: é muito raro encontrar nessas obras qualquer menção datada a eventos da política do país, a não ser por vagas passagens nas quais não se citam nomes nem fatos, ainda que o cenário fosse pleno de eventos fundamentais para a definição da complexidade que caracterizou essa década. Eventos como a Revolução de 1930, a Revolução de 1932 e a Constituição de 1934, para citar apenas alguns, costumam não fazer parte de modo direto da matéria abordada por tais romancistas, indicando que o importante naquele momento era fazer ecoar a voz nordestina que, subdesenvolvida, pobre, sofrida, apresentava-se como a atração principal da época, pelo menos para o público leitor. Paira um sentimento de novidade, de procura por uma nova literatura, processo reforçado pelos novos tempos que se impõem, graças às mudanças em curso.
"Um dia desses Jorge Amado falou sobre a descentralização do romance da metrópole para a província, como eles chamam gostosamente os Estados do Norte... Acontece que os motivos explorados nos últimos dez anos pelos escritores da metrópole estão em franca decomposição. Eram os ambientes da classe alta, os dramas sexuais de determinados indivíduos em uma sociedade em pleno gozo de suas faculdades físicas. Excessos e requintes de um mundo em véspera do aniquilamento total" (Jurema, 1934, p. 217).

Assim como Jorge Amado, outros autores oriundos do Nordeste se revelariam por esses caminhos expressando uma nova literatura, "dotada de coragem moral de conhecer a verdade [...] talvez por ser ali mais dolorosa a realidade, menos conhecida a terra, mais ingrato o clima, mais desiguais as condições de vida, mais intenso o drama humano" (Oliveira, 1939, p. 115). Trata-se de elementos com grande potencial dramático, capazes de servir de plataforma para toda uma geração de escritores que pretendem operar uma transformação literária, centrando-se não apenas na dimensão social do fazer artístico, ainda que seja essa a característica mais destacada. Há uma proposta ampla, que envolve a introdução e/ou readequação de vários elementos, tais como personagens, linguagem, cenários, comportamentos, tradições - para além das questões sociais que predominam sob o olhar da crítica.

Em 1936, Gilberto Freyre, referindo-se ao conjunto de obras da década de 1930 produzidas até então, escreve: “[...] se deu de repente, entre nós, uma predominância do forte sobre o belo; do próprio feio sobre o bonito" (Freyre, 1936, p. 16). Longe de apresentar-se como um rebaixamento, 
a observação de Freyre constata a prática não apenas de uma "causa" social, mas também de uma proposta estética, a ponto de, mais à frente, no mesmo artigo, comparar Jorge Amado e José Lins do Rego a Sherwood Anderson e John dos Passos, autores americanos tidos por Freyre como praticantes de um "vigor híbrido" ou "um certo hibridismo entre o sociológico e o literário”. A esse conjunto de características deve-se somar também a capacidade de tais homens de letras, em especial Jorge Amado, de se lançarem em "terra desconhecida", ou seja, o desafio de praticarem uma literatura nova em todos os sentidos, estéticos e formais. "Norte, na literatura de hoje, é sinônimo de renovação e de audácia" (Castro, 1935, s.p.).

Assim, o rótulo de "romance social" limita as qualidades literárias dessa voz insurgente, atribuindo a ela características ligadas especificamente à política, à ideologia e à denúncia social, pouco se detendo na análise das qualidades literárias, estéticas e formais desse rol de autores, em especial de Jorge Amado. Colocar etiquetas é uma prática que se mostra sempre como um artifício didático útil para a compreensão dos fenômenos, mas, também, reducionista, deixando espaços vazios a serem ocupados por novas visões e abordagens. E somente por essas frestas, ignoradas em favor de um didatismo pontual, é que se podem operar transformações na compreensão das manifestações artísticas.

"Não se deve, no entanto, exagerar as restrições a esses romances, a começar pelos de Jorge Amado, cuja grandeza vem exatamente de mergulhar sem medo em todos os paradoxos que sua opção literária e ideológica implicava. De um modo ou de outro, eles fizeram o esforço de olhar para além dos limites de sua própria classe e integraram à cultura letrada brasileira elementos até aquele momento tidos como bastardos ou nitidamente inferiores" (Bueno, 2002, p. 270).

Essa movimentação de expressões literárias, aparecendo no mercado com vistas a se consolidarem ao longo da década de 1930, atrela-se a um marco fundamental na estrutura política e social do país: a chamada Revolução de 1930, ou seja, o embate contra as oligarquias dominantes empreendido por Getúlio Vargas, que toma o poder e assume a presidência com um discurso questionador à decadente Primeira República. Abre-se uma via de acesso à literatura para todos esses autores que viriam a se consolidar ao longo da década, não motivados pela anuência ao novo regime, mas, sim, pela oportunidade de manifestações múltiplas que então se descortinava.

"O movimento de outubro [...] foi um eixo e um catalisador: um eixo em torno do qual girou de certo modo a cultura brasileira, catalisando elementos dispersos para dispô-los numa configuração nova. Neste sentido foi um marco histórico, daqueles que fazem sentir vivamente que houve um 'antes' diferente de um 'depois' [...]” (Candido, 1989, p. 181).

A prosa, "liberta e amadurecida" (Candido, 1965, p. 147), pôde seguir novos caminhos, e, nesse berço de novas ideias, novos mercados, novos impulsos, surgem as novas propostas literárias de Jorge Amado. Mais especificamente, há um "grito" coletivo, uma 
expressão de mudança dentro de um projeto revolucionário, no qual é clara a influência dos movimentos de esquerda internacionais, especificamente o comunismo.

"Nós, da geração de 1930, nascemos da Guerra e da Revolução Russa. Somos uma geração de romancistas. O sentido de documento, de grito, é sem dúvida a coisa que surge mais clara no novo romance brasileiro... Os novos romancistas, brasileiros, não apenas os do Norte, não acreditaram mais em brasilidade, em verdeamarelismo. Viram mais longe. Viram esse mundo ignorado que é o Brasil. E o Brasil é um grito, um pedido de socorro. Grito, sim, de populações inteiras, perdidas, esquecidas, material imenso para imensos livros. Romancistas novos do Brasil, revolucionários ou reacionários, nos seus livros vive um clamor, um grito que era desconhecido e que começa a ser ouvido. Hoje, era do comunismo e do arranha-céu, da habitação coletiva, o romance tende para a supressão do Herói, do personagem. Cito exemplos daqui: em Menino de Engenho, o personagem não é o menino Carlos de Melo. É o engenho. [...] A seca é o personagem de $O$ Quinze, a cadeia o de João Miguel. E não são as fábricas os heróis de Os Corumbas? Em A Selva do português Ferreira de Castro é a floresta que domina tudo, como em Cacau eu pretendi que fossem os frutos amarelos que comandassem os coronéis e os trabalhadores" (Amado, 1934, p. 48).

No momento em que escreve tal texto, Jorge Amado estava imbuído da missão de consolidar os critérios que ele mesmo vinha formulando para definir as características desse novo romance. Não por acaso, procura usá-los para classificar as obras mais importantes que então circulavam. A maneira com que substitui o herói humano pelos ambientes coletivos (engenho, cadeia, floresta e até os seus "frutos amarelos") revela-se uma tentativa discutível de dar corpo às suas ideias. O que não o compromete literariamente, até porque era importante, naquele momento, ter ideias.

A prova disso é que, pouco antes de publicar esse texto, Jorge Amado havia lançado a sua segunda obra, Cacau (1933), em cujo Prefácio, largamente mencionado na crítica da época e também nos estudos das décadas seguintes, encontra-se o uso da expressão "romance proletário". Ao mesmo tempo em que põe em dúvida se esse seria o "gênero" que então praticava, também o define - uma maneira sutil de tomar a dianteira da questão. E menciona "a vida dos trabalhadores das fazendas de cacau do sul da Bahia" (Amado, 1974, p. 121) como o núcleo do conteúdo da obra, numa óbvia tentativa de se apropriar dessa espécie literária, processo que pode até ter sido inconsciente, o que não faz diferença. Muito tempo depois, o seu olhar sobre esse momento se mostra sobretudo crítico e bem mais equilibrado:

"Fazer um romance proletário era, evidentemente, pura pretensão da minha parte. A consciência proletária ainda estava em formação num país que apenas começava a se industrializar e onde não existia, propriamente, uma classe operária; o que havia era o trabalhador manual - e, neste ponto, a descrição da vida dos trabalhadores rurais é o que torna Cacau muito real" (Raillard, 1990, p. 55).

Seja como for, a obra provoca um grande impacto no mercado. A Editora Ariel 
fez uma tiragem de 2 mil exemplares, em agosto de 1933, que foram apreendidos pela polícia do Rio de Janeiro devido à "violenta mensagem social". Manobras políticas permitiram, no entanto, que o livro fosse liberado pela justiça, e esse rápido incidente alavancou o interesse do público: a edição esgotou-se em 40 dias, quando foi feita nova tiragem, desta vez de 3 mil exemplares (Hallewell, 1985, p. 345). Além dessa publicidade, elementos estéticos e formais garantiram a popularidade da obra; de certa maneira, estiveram presentes ao longo da carreira do autor, perpetuando a popularidade que gozou nas décadas seguintes. Não só a voz nordestina, a adequação ao momento político e social, ao discurso engajado de esquerda, mas também aspectos estéticos foram fundamentais para a consagração do autor. A literatura de Jorge Amado, já em Cacau, "opõe-se ao intelectual bacharel", aos "homens de letras", que até então ocupavam o centro do campo intelectual, com seus "livros bonitos", de "fraseado", com sinônimos cautelosamente empregados, "sem repetição de palavras" (Amado, 1933, apud Almeida, 1979, p. 94).

\section{CONCLUSÃO}

Não se pode negar que as qualidades de Jorge Amado foram fundamentais para que ele se destacasse, na primeira metade da década de 1930, como protagonista de reconhecida importância no mercado editorial. Ousado e inovador, ainda que muito jovem (ou por isso mesmo), disposto a se lançar em novas proposições estéticas e formais, foi capaz, também, de conquistar um espaço único na imprensa da época, expressando suas opiniões literárias de maneira contundente e provocadora, sem hesitar em lançar afirmações polêmicas, em confrontar-se com autores e críticos consagrados e em fazer valer sua opinião em ambientes normalmente hostis para jovens escritores - lembrando que nesse período, entre 1930 e 1935, Amado tinha entre 18 e 23 anos.

Mas esses não são os únicos ingredientes de sua "fórmula de sucesso". Devem-se considerar também dois fatores principais, aqui expostos, que se casam por uma "feliz" coincidência. O primeiro diz respeito aos elementos conjunturais da política e da cultura que pavimentam um cenário muito propício ao florescimento da literatura brasileira nos anos 1930 e, consequentemente, da obra de Jorge Amado. Expansão pujante em todos os sentidos: proliferação de autores, editoras e revistas literárias, aumentos exponenciais de tiragens e vendas, e, em consequência desses fatores, uma produção de textos canônicos que se eternizaram pela voz de, pelo menos, alguns dos escritores da época. O segundo deles, tendo em vista o talento literário do jovem escritor, seu senso de oportunidade, sua ousadia e a consistente convicção de suas ideias, diz respeito à grande vocação de Jorge Amado para se tornar, naquele momento, uma celebridade, um campeão de vendas e um protagonista do romance de 1930, incluindo a sua capacidade de racionalizar e tornar explícita a definição de caráter estético e formal da literatura que então despertava. Em certa medida, talento e circunstâncias favoráveis são capazes de criar heróis. 


\section{REFERÊNCIAS}

ALMEIDA, Alfredo Wagner Berno de. Jorge Amado: política e literatura. Rio de Janeiro, Campus, 1979.

ALMEIDA, José Maurício Gomes de. A tradição regionalista no romance brasileiro (1875-1945). 2a ed. Rio de Janeiro, Topbooks, 1999.

AMADO, Jorge. "Evolução da poesia brasileira". A Batalha. Rio de Janeiro, 20/11/1932, p. 1.

AMADO, Jorge. "A academia e o Brasil Integral". Revista Momento, ano I, n. 2. Rio de Janeiro, 1\%/12/1933a, s/p.

AMADO, Jorge. "O gororoba". Boletim de Ariel, ano III, n. 3. Rio de Janeiro, 3/12/1933b, p. 71.

AMADO, Jorge. "Apontamentos sobre o moderno romance brasileiro". Lanterna Verde, n. 1. Rio de Janeiro, maio/1934a, pp. 48-51.

AMADO, Jorge. "Trecho de biografia". Gazeta de Notícias. Rio de Janeiro, 5/12/1934b, pp. 3-5.

AMADO, Jorge. "A volta de um romancista". Boletim de Ariel, ano IV, n. 6. Rio de Janeiro, mar./1935a, pp. 158-9.

AMADO, Jorge. "Poeta sem assunto". Revista Acadêmica, ano III, n. 15. Rio de Janeiro, nov./1935b, p. 6.

AMADO, Jorge. "Romance moderno". Diário de Notícias. Rio de Janeiro, 22/12/1935c, p. 19. AMADO, Jorge. País do carnaval, Cacau, Suor. São Paulo, Martins, 1974.

AMADO, Jorge. Navegação de cabotagem. Rio de Janeiro, Record, 1992.

ANDRADE, Mário de. O empalhador de passarinho. São Paulo, Martins, 1972.

BUENO, Luís. "Os três tempos do romance de 30". Teresa, n. 3. São Paulo, 26/12/2002, pp. 254-83.

BUENO, Luís. Uma história do romance de 30. São Paulo, Edusp, 2015.

CANDIDO, Antonio. Educação pela noite e outros ensaios. São Paulo, Ática, 1989.

CANDIDO, Antonio. Formação da literatura brasileira. 2 vols. Belo Horizonte/Rio de Janeiro, Itatiaia, vol. 2 (1836-1880), s/d.

CANDIDO, Antonio. Literatura e sociedade. São Paulo, Nacional, 1965.

CANO, Wilson. "Da década de 1920 a 1930: transição à crise e à industrialização no Brasil". Revista de Políticas Públicas, v. 16, n. 1, jan.-jun./2012, pp. 79-90.

CASTRO, Moacyr Werneck de. "Sobre um romance do norte". Revista Acadêmica, ano II, n. 10. Rio de Janeiro, abr./1935, s.p.

DUARTE, Eduardo de Assis. Jorge Amado: romance em tempo de utopia. Rio de Janeiro, Record, 1996.

FREYRE, Gilberto. "Sociologia e literatura". Lanterna Verde, n. 4. Rio de Janeiro, nov./1936, pp. 15-8.

HALLEWELL, Laurence. O livro no Brasil (sua história). São Paulo, T.A. Queiroz/Edusp, 1985. JORGE AMADO: 30 anos de literatura. São Paulo, Martins, 1961.

JUREMA, Aderbal. "Literatura revolucionária e reacionária". Boletim de Ariel, ano III, n. 8. Rio de Janeiro, maio/1934, p. 217.

LAFETÁ, João Luiz. 1930: a crítica e o modernismo. São Paulo, Editora 34/Duas Cidades, 2000. 
MELLO, Mário Vieira de. Desenvolvimento e cultura. O problema do esteticismo no Brasil.

São Paulo, Nacional, 1963.

OLIVEIRA, José Osório de. História breve da literatura brasileira. Lisboa, Inquérito, 1939.

PAES, José Paulo. De Cacau a Gabriela, um percurso pastoral. Salvador, Casa das Palavras/ Fundação Jorge Amado, 1991.

RAILLARD, Alice. Conversando com Jorge Amado. Rio de Janeiro, Record, 1962.

SALLA, Thiago Mio. "Literatura, política e legitimação institucional: o romance de 1930 e o Modernismo de 1922 segundo a retórica estado-novista". Teresa, n. 16. São Paulo, 2015, pp. 117-134.

TATI, Miécio. Jorge Amado: vida e obra. Belo Horizonte, Itatiaia, 1961. 